\title{
Shallow input processing does not induce environmental context-dependent recognition
}

\author{
STEVEN M. SMITH, EDWARD VELA, and JOHN E. WILLIAMSON \\ Texas A\&M University, College Station, Texas
}

\begin{abstract}
Four experiments examined Smith's (1986) hypothesis that environmental context (EC) dependent recognition memory would be greater following shallow processing than following deep processing. All experiments found effects of level of processing manipulations, yet none found evidence of EC-dependent recognition. Experiment 3 included recognition reaction times as well as accuracy levels. It was concluded that Smith's (1986) EC-dependent recognition memory findings must have been due to some characteristic of the incidental learning task used in that study other than its shallow processing level.
\end{abstract}

List-learning studies have found that manipulations of environmental contexts or states during input and test affects recall but not recognition memory (e.g., Bartlett \& Santrock, 1979; Eich, 1980; Godden \& Baddeley, 1975, 1980; Smith, Glenberg, \& Bjork, 1978). Numerous studies have failed to find evidence of environmental context (EC)-dependent recognition (e.g., Eich, 1985; Fernandez \& Glenberg, 1985; Godden \& Baddeley, 1980; Jacoby, 1983; Smith et al., 1978), which is the focus of the present set of experiments.

The idea that background cues are less effective when other cues are used has been expressed in various ways (e.g., Eich, 1980; Eich, Weingartner, Stillman, \& Gillin, 1975; Smith, 1986; Smith et al., 1978). This principle explains that a recognition test provides considerably more cues related to the studied items than does a recall test; therefore, the numerous cues reduce the effectiveness of background context cues when recognition tests are used. Context cues, according to this reasoning, are relatively more important when better cues are not provided, as on a free recall test.

A growing number of studies, however, have found significant effects of environmental manipulations (Canas \& Nelson, 1986; Smith, 1985, 1986; Smith \& Vela, 1986), imagined context manipulations (e.g., Geiselman \& Bjork, 1980; Krafka \& Penrod, 1985; Malpass \& Devine, 1981), and state manipulations (e.g., Gage \& Safer, 1985; Leight \& Ellis, 1981) on recognition memory. Although findings of context-dependent recognition may appear to contradict the principle that context cues lose their effectiveness when good cues are provided, many of the findings

\footnotetext{
The research reported here was supported by National Institute of Mental Health Grant 1 R01 MH39977-01 awarded to Steven M. Smith. Experiment 4 was based on a master's thesis by Edward Vela. The experiments were presented in part at the 1987 annual meeting of the Southwestern Psychological Association in New Orleans, LA. Thanks are due to Nancy Cohen for collecting the data for Experiments 1 and 2. Requests for reprints should be sent to Steven M. Smith, Department of Psychology, Texas A\&M University, College Station, TX 77843.
}

may have occurred because better cues were restricted from being encoded.

Geiselman and Bjork (1980) found voice-dependent recognition following a shallow nonassociative rehearsal task, but not after an elaborative rehearsal task. Smith (1986) found EC-dependent recognition following an incidental short-term memory task, but not after instructions that a long-term memory test would be given. These results suggest that shallow (see Craik \& Tulving, 1975) or nonassociative input processing makes recognition more dependent on context. The four experiments in the present study tested the hypothesis that shallow input processing will result in EC-dependent recognition memory.

\section{EXPERIMENT 1}

The present experiments used incidental learning tasks related to those used by Craik and Tulving (1975) to induce different levels of processing. Four different orienting tasks were used (between subjects) in Experiment 1: a shallow task that required processing of graphemic information (counting the vowels), a task that required processing phonemic information (generating a rhyme), a semantic task (generating an associate), and an imagery task (generating an image). Recognition testing occurred in an environmental context that was either the same as or different from the room where the list was input. We predicted that shallower processing would cause both lower levels of recognition and a greater performance advantage for samecontext (SC) than for different-context (DC) conditions.

\section{Method}

Participants. The 184 student volunteers were recruited from the introductory psychology classes at Texas A\&M University. Partial fulfillment of a course requirement was earned by each volunteer's participation.

Materials. The 160 high-frequency English nouns used in the present study were from Kucera and Francis's (1967) word frequency norms. Of those, 40 were used on the input list and 120 more used as distractors on the four-alternative forced-choice (4AFC) recognition memory test.

The input list, presented via audiotape, was spoken by a male voice at a rate of one word every $10 \mathrm{sec}$. The 4AFC recognition test was typed 
on a single piece of paper. Each of the $\mathbf{4 0}$ test items consisted of a target and three distractors, randomly arranged.

Design and Procedure. Students participated in groups ranging in size from 4 to 10 per session. Each participant was given a response page with 40 numbered blank spaces. At the top of each page was a title and instructions, with each title and instruction set corresponding to a different level of processing (LOP). The four titles used were Vowel Fluency Test, Rhyming Fluency Test, Associative Fluency Test, and Image Fluency Test. The vowel test required participants to write the number of vowels in the corresponding numbered space for each word spoken on the tape recording. The rhyme test required participants to write a rhyme for each word heard on the tape. The association test required participants to write down a free associate for each word. The imagery test required participants to rate the vividness of each image they formed for each word referent.

After hearing the taped list and recording their responses, participants left the room for $5 \mathrm{~min}$. Half the subjects in each of the four instruction groups were returned to their original environments, and half were taken to a test room, which was selected to be as different as possible from the input room. Participants were then given the 4AFC recognition test.

\section{Results and Discussion}

A $2 \times 4$ (test context $\times$ LOP) analysis of variance (ANOVA) was computed, using total number of words correctly recognized as the dependent measure. There were 40 test items, and chance performance was 10 correct. There was a significant effect of $\operatorname{LOP}[F(3,176)=$ $18.87, p<.001, M S e=22.45$ ]. Newman-Keuls pairwise comparisons found that the imagery and association groups recognized more words than the rhymes and vowels groups $(\alpha=.05$, critical difference $=3.65)$. Performance for imagery and association groups did not differ from each other, and there was no difference between the rhymes and vowels groups.

There was no effect of test context $(F<1)$. The test context $\times$ LOP interaction, which would have been evidence in support of the experimental hypothesis, was not significant $[F(3,176)=1.35, p=.26, M S e=22.45]$. For the four different levels of processing, the largest context effect was in the rhymes condition (Table 1). Not even a hint of an effect occurred, however, following the vowel counting task.

Although the results did not support the experimental hypothesis, a hint of an effect appeared for the rhymes group. Because the rhyming and vowel counting tasks both resulted in poor recognition performance, indicating shallower processing, it was expected that EC manipulations would affect recognition following both orienting tasks. The evidence from Experiment 1, therefore, did not clearly support or refute the experimental hypothesis.

Table 1

Number of Items Recognized as a Function of Test Context and Level of Processing in Experiment 1

\begin{tabular}{lcc}
\hline & \multicolumn{2}{c}{ Test Context } \\
\cline { 2 - 3 } Level of Processing & Same & Different \\
\hline Counting Vowels & 32.45 & 33.20 \\
Making Rhymes & 33.20 & 30.20 \\
Free Association & 38.05 & 37.60 \\
Generating Imagery & 37.30 & 37.80 \\
\hline
\end{tabular}

Note-There were 40 possible hits.
Table 2

Number of Items Recognized as a Function of Test Context and Level of Processing in Experiment 2

\begin{tabular}{lcc}
\hline & \multicolumn{2}{c}{ Test Context } \\
\cline { 2 - 3 } Level of Processing & Same & Different \\
\hline Counting Vowels & 29.20 & 28.80 \\
Making rhymes & 28.80 & 28.70 \\
Free Association & 37.90 & 36.05 \\
Generating Imagery & 37.80 & 36.40 \\
\hline
\end{tabular}

Note-There were 40 possible hits.

\section{EXPERIMENT 2}

Experiment 2 was conducted to replicate the results of Experiment 1.

\section{Method}

The design, procedure, and materials were the same as those used in Experiment 1, except that a 10-min retention interval was used to try to get performance farther below the ceiling. It was expected that EC dependence would more likely be observed under such circumstances. The 174 introductory psychology students who served as subjects fulfllled part of a course requirement by participating in Experiment 2.

\section{Results and Discussion}

A $2 \times 4$ (test context $\times$ LOP) ANOVA was computed, using number of correct recognitions as the dependent measure. There were $\mathbf{4 0}$ test items, with chance performance at 10 correct. The results are shown in Table 2 . Overall, the scores were poorer than in Experiment 1, indicating that the 10-min delay reduced performance as intended. As in Experiment 1, there was a robust effect of $\operatorname{LOP}[F(3,166)=28.71, p<.001, M S e=28.50]$. Again, the association and imagery groups scored well above the vowels and rhymes groups, indicating the success of the LOP manipulation.

No effect was found for test context, $(F<1)$, and there was no interaction of test context and level $[F(3,166)=$ $1.49, p=.22, M S e=28.50]$. The largest effects of test context were in the groups with deeper input processing. These findings refute the hypothesis that EC-dependent recognition should occur after shallow input processing.

\section{EXPERIMENT 3}

In an attempt at greater sensitivity to context-dependent recognition, measures of both latency (reaction time, or RT) and accuracy were collected on the recognition test in Experiment 3. The three levels of processing used were manipulated within participants.

\section{Method}

Participants. The $\mathbf{4 0}$ student volunteers earned partial fulfillment of an introductory psychology course requirement for their participation.

Materials. The $\mathbf{3 0}$ targets and $\mathbf{3 0}$ distractors were common one-syllable English nouns that were printed on slides. The 30 orienting questions were also printed on slides. Ten of the orienting questions were designed to induce-shallow graphemic processing (e.g., "'THREE VOWELS?'), 10 were for somewhat deeper processing at an acoustic level (e.g., "'RHYMES WITH WHALE?'), and 10 were for deep semantic process- 
ing (e.g., "BODY OF WATER?'). Half of each set of orienting questions were correctly answered with "yes" and half with "no." Orienting responses were written by participants on a response page that contained 30 numbered lines with " $Y$ " (for "yes") and " $N$ " (for "no") on each line.

The slide projector with its tachistoscopic shutter was controlled by an Apple computer. Hand controllers were used by participants to respond on the recognition test.

Design and Procedure. Each orienting question was followed by a target word that was used to answer the question immediately preceding it. Participants were asked to respond quickly to each of the $\mathbf{3 0}$ orienting questions by responding "yes" or "no."

After the 30 orienting questions were completed, participants either went to another room in another building on campus, which took $5 \mathrm{~min}$, or waited in the hall for 5 min during the retention interval before returning to the original room.

The timed recognition test presented each of the targets and distractors, and participants responded to each by pressing the right-hand controller to indicate that a word was "old" and the left to indicate "new." They were asked to respond as accurately and quickly as possible.

\section{Results and Discussion}

A $2 \times 3$ (test context $\times$ level) ANOVA was computed, using number of hits as the dependent measure. There was a significant effect of $\operatorname{LOP}[F(2,76)=65.45, p<.0001$, $M S e=2.01]$, indicating optimal performance in the deep processing condition and poorest recognition in the shallow processing condition (Table 3). Although there were more hits in the SC condition than in the DC condition, the effect was not significant $[F(1,38)=1.51, p=.23$, $M S e=4.03]$. The largest context effect (i.e., difference between SC and DC conditions) was for the shallowest processing condition. The test context $\times$ LOP interaction, however, was not significant $[F(2,76)<1]$.

A $2 \times 3$ (test context $\times$ LOP) ANOVA was computed, using RT for hits as the dependent measure. There was no effect of $\operatorname{LOP}[F(2,76)=1.01, p=.37, M S e=.05]$, as shown in Table 3. Although correct recognition responses were slightly faster in the SC condition, the effect of test context was not significant $(F<1)$, and there was no significant interaction $(F<1)$.

The failure to find effects of test context for any measure at any LOP again rejects the hypothesis that shallower input processing should be more likely to produce the necessary conditions for EC-dependent recognition. It is interesting, however, that SC participants were better (but not significantly) than DC participants on both accuracy and latency scores. It may be that if latency and accuracy scores could be meaningfully combined, a test context effect might emerge from such results. It may also

Table 3

Mean Reaction Times and Numbers of Hits in Experiment 3

\begin{tabular}{lccc}
\hline & \multicolumn{3}{c}{ Level of Encoding } \\
\cline { 2 - 4 } Context & Shallow & Medium & Deep \\
\hline \multicolumn{4}{c}{ Number of Hits } \\
Same & 5.75 & 7.30 & 9.25 \\
Different & 5.05 & 7.10 & 8.80 \\
& & & \\
& Hit Reaction Time & \\
Same & .831 & .916 & .873 \\
Different & .870 & .908 & .951 \\
\hline
\end{tabular}

Note-There were 10 possible hits at each level of processing. Reaction times are given in seconds. be that the speeded responding in the present experiment made the test slightly more context sensitive.

\section{EXPERIMENT 4}

The hypothesis that shallow input processing would lead to EC-dependent recognition also predicts that the less associative or categorical structure encoded with a list of words, the greater the effect of a room manipulation on recognition memory. It was the intention of Experiment 4 to test both of these predictions.

\section{Method}

Participants. The 174 student volunteers who served as participants fulfilled part of an introductory psychology course requirement by participating in the experiment.

Materials. The 144 categorized English nouns selected for targets and distractors in Experiment 4 were chosen from Marshall and Cofer's (1970) free association norms. The input list consisted of 48 words corresponding to six categories of eight exemplars each. Each word was printed on a separate slide. The recognition test, presented on an audiotape at a 5-sec rate, included all 144 items randomly intermixed. On the input list, an orienting instruction appeared on a slide directly preceding each word. For the shallow LOP conditions, each word was preceded by an orienting slide, which contained a consonant-vowel three-letter combination (CVC, CVV, CCV, VVC, VCV, or VCC) to be found in the subsequent slide. For the deep LOP conditions, the target slides were preceded by a "READY" slide. In the blocked condition, all items in a category were presented together, whereas in the random condition, they were mixed with items from all other categories. There were two types of categories, semantic and graphemic. Semantic categories were classified according to meaning (e.g., birds, spices), and graphemic items were classified by consonant-vowel pattern (e.g., ROBIN $=$ CVC, BLUEBIRD $=\mathrm{CCV})$. Each word represented an exemplar of both a semantic and a graphemic category.

Four learning lists were constructed such that two were used for the deep LOP conditions and two were used for the shallow LOP conditions. One of each pair used a blocked presentation (semantic or graphemic categories) and the other a random presentation (same semantic or graphemic categories but randomly presented).

Design and Procedure. Participants met in groups of no more than 10. Each group began in either Room A or Room B. All participants were told that they would be participating in an experiment investigating the effects of word classification on subsequent word classification tasks.

In all conditions words were shown individually on slides at a 5-sec rate. The first six words served as practice trials that provided an example of each category to be encountered. Participants in the shallow LOP conditions were told that they were to search for the consonant-vowel three-letter pattern specified in the preceding probe slide and to write down the corresponding letters from the word subsequently presented.

Participants in the deep LOP conditions were told that, following each probe slide (the word "READY"), a target word would be presented. Their task was to write a free associate for each target.

After all target words were presented, participants were given an immediate surprise free recall test. This test served as a manipulation check to determine the degree to which participants formed list structure cues. Evidence of clustering was used to determine whether in fact such cues were formed.

After the recall test, all participants were sent to a waiting area for approximately $20 \mathrm{~min}$. Those in the SC conditions returned to the original learning room. Those in DC conditions went to a new room. Once participants arrived at their test room, they were given a surprise recognition test. Test items were presented on an audiotape at a 5-sec rate. Participants recorded their recognition judgments on a provided response sheet.

\section{Results and Discussion}

As a manipulation check for the LOP and list structure manipulations, two separate $2 \times 2$ (LOP $\times$ list structure) 
Table 4

$d^{\prime}$ as a Function of Test Context, Level of Processing, and List Structure in Experiment 4

\begin{tabular}{cccc}
\hline & & \multicolumn{2}{c}{ Test Context } \\
\cline { 3 - 4 } Level of Processing & List Structure & Same & Different \\
\hline Deep & Block & 4.08 & 3.64 \\
Deep & Random & 3.62 & 3.68 \\
Shallow & Block & 1.15 & 1.03 \\
Shallow & Random & 1.14 & 1.07 \\
\hline
\end{tabular}

ANOVAs were computed for the free recall data, using total recalled and clustering scores as the respective dependent measures.

The ANOVA using total words recalled as the dependent measure showed a robust effect of $\operatorname{LOP}[F(1,170)=$ $809.35, p<.001, M S e=16.134]$. No effect was found for list structure $[F(1,170)=1.04, p=.30, M S e=$ 16.134], but the LOP $\times$ list structure interaction was significant $[F(1,170)=6.44, p=.011]$. Newman-Keuls pairwise comparisons showed that the blocked list structure resulted in better recall performance only for list items processed at the deep LOP ( $\alpha=.05$, critical difference $=1.72$ ). Although these results indicate a successful LOP manipulation, the important analysis for the list structure manipulation is one using the clustering scores derived from the recall protocols as the dependent measure. The results of this analysis again showed a persistent effect of LOP $[F(1,170)=57.90, p<.001, M S e=832.58]$. No effect was found for list structure $[F(1,170)=1.36, p=$ $.24, M S e=832.58]$, and there was no list structure $\times$ LOP interaction $(F<1)$. Although strong and consistent effects were found for LOP, differences between the levels of list structure were not demonstrated.

The analysis of recognition performance for $d^{\prime}$ used a $2 \times 2 \times 2$ (test context $\times$ LOP $\times$ list structure) ANOVA (Table 4). As in previous analyses, a significant effect of LOP was found $[F(1,166)=604.34, p<.001, M S e=$ .504], with the better performance following deep processing. The effect of test context was not significant $[F(1,166)=1.52, p=.219, M S e=.504]$, nor were the critical interactions of test context and LOP $(F<1)$ and test context and list structure $[F(1,166)=2.07, p=.152$, $M S e=.504]$. Consistent with the previous three experiments, LOP did not affect EC-dependent recognition.

\section{GENERAL DISCUSSION}

Level of input processing appears to have been adequately manipulated in all experiments, yet there was no clear effect of EC manipulations on recognition accuracy at any level of processing. The results, which include observations from a total of 572 participants from four experiments, reject the hypothesis that shallow input processing leads to EC-dependent recognition.

Although the experimental hypothesis was rejected, some interesting findings emerged from the results. The findings of Experiment 3 suggested that EC manipulations may have affected recognition, but only if both accuracy and latency measures were considered. The speeding up of recognition with the RT test may have made memory somewhat more context sensitive. In addition, although there was no main effect of test context in any of the four experiments, the trend in almost every context comparison (SC vs. DC) favored same-context performance.
If not shallow processing, then what did produce the conditions for observing EC-dependent recognition in Smith's (1986) three experiments? The most promising remaining hypothesis was advanced by Geiselman and Bjork (1980). It states that maintenance rehearsal of words involves relatively little semantic and associative information, so relatively more contextual information is encoded. They reasoned that when maintenance rehearsal spans more seconds of time, contextual information becomes relatively more important for memory of the words. It may be that the longer duration of shallow rehearsal, and not simply shallow processing per se, may have contributed to Smith's (1986) findings.

\section{REFERENCES}

Bartlett, J. C., \& Santrock, J. W. (1979). Affect-dependent episodic memory in young children. Child Development, 5, 513-518.

Canas, J. J., \& Nelson, D. L. (1986). Recognition and environmental context: The effect of testing by phone. Bulletin of the Psychonomic Society, 24, 407-409.

Craik, F. I. M., \& Tulving, E. (1975). Depth of processing and the retention of words in episodic memory. Journal of Experimental Psychology: General, 104, 268-294.

Eich, J. E. (1980). The cue-dependent nature of state-dependent retrieval. Memory \& Cognition, 8, 157-173.

EICH, J. E. (1985). Context, memory, and integrated item/context imagery. Joumal of Experimental Psychology: Leaming, Memory, \& Cognition, 11, 764-770.

Eich, J. E., Weingartner, H., Stillman, R. C., \& Gilun, J. C. (1975). State-dependent accessibility of retrieval cues in the retention of a categorized list. Joumal of Verbal Learning \& Verbal Behavior, 14, 408-417.

FernandeZ, A., \& GlenberG, A. M. (1985). Changing environmental context does not reliably affect memory. Memory \& Cognition, 13, 333-345.

GAGE, D. F., SAFER, M. A. (1985). Hemisphere differences and the mood state-dependent effect for recognition of emotional faces. Journal of Experimental Psychology: Leaming, Memory, \& Cognition, 11, $752-763$.

Geiselman, R. E., \& BJoRK, R. A. (1980). Primary versus secondary rehearsal in imagined voices: Differential effects on recognition. Cognitive Psychology, 12, 188-205.

GODDEN, D. R., \& BadDELEY, A. D. (1975). Context-dependent memory in two natural environments: On land and underwater. British Journal of Psychology, 66, 325-332.

GODDEN, D. R., \& BADDELEY, A. D. (1980). When does context influence recognition memory? British Journal of Psychology, 71, 99-104.

JACOBY, L. L. (1983). Perceptual enhancement: Persistent effects of an experience. Journal of Experimental Psychology: Learning, Memory, \& Cognition, 9, 21-38.

KrafKa, C., \& Penrod, S. (1985). Reinstatement of context in a field experiment on eyewitness identification. Journal of Personality \& Social Psychology, 49, 58-69.

KUČERA, H., \& FRANCIS, W. N. (1967). Computational analysis of presentday American English. Providence, RI: Brown University Press.

LEIGHT, K. A., \& Elus, H. C. (1981). Emotional mood states, strategies, and state-dependency in memory. Journal of Verbal Learning \& Verbal Behavior, 20, 251-266.

Malpass, R. S., \& Devine, P. G. (1981). Guided memory in eyewitness identification. Journal of Applied Psychology, 66, 343-350.

Marshall, G. R., \& CoFer, C. N. (1970). Single-word free association norms for 328 responses from the Connecticut cultural norms for verbal items in categories. In L. Postman \& G. Keppel (Eds.), Norms of word associations (pp. 321-360). New York: Academic Press.

SMITH, S. M. (1985). Environmental context and recognition memory reconsidered. Bulletin of the Psychonomic Society, 23, 173-176.

SMITH, S. M. (1986). Environmental context-dependent recognition using a short-term memory task for input. Memory \& Cognition, 14, 347-354.

Smith, S. M., Glenberg, A. M., \& BJoRK, R. A. (1978). Environmental context and human memory. Memory \& Cognition, 6, 342-353.

Smith, S. M., \& Vela, E. (1986, May). Context-dependent eyewitness recognition. Paper presented at the annual meeting of the Midwest Psychological Association, Chicago, IL.

(Manuscript received April 26, 1988.) 